\title{
Territórios Senhoriais, Fronteiras Diocesanas: O Poder Senhorial-Episcopal em Castela no Século XII
}

\author{
Seigniories territories, Diocesan Borders: The Episcopal Seigniorial Power in \\ Castle in the XII century
}

\begin{abstract}
Bruno Gonçalves Alvaro ${ }^{1}$
${ }^{1}$ Doutor em História Comparada pela Universidade Federal do Rio de Janeiro e Pós-Doutorando em História pela Universidade de Brasília (2020-2021), sob a supervisão de Profa. Dra. Maria Filomena P. da Costa Coelho. Docente do Programa de Pós-Graduação em História e do Departamento de História da Universidade Federal de Sergipe. E-mail: brunoalvaro@yahoo.com.br.
\end{abstract}

Recebido em 22 de março de 2021; Aceito em 25 de junho de 2021

DOI: $10.12957 /$ nearco.2021.58574

\section{Resumo}

Este artigo analisa a ação do poder senhorial-episcopal nos tensionamentos presentes nos territórios senhoriais das dioceses castelhano-leonesas de Sigüenza, Osma e Tarazona em meados do século XII. Por meio da documentação diplomática, são problematizadas as relações de negociação entre os bispos nos ajustes das delimitações de suas fronteiras diocesanas e o peso que o poder senhorial exercia na resolução desses conflitos.

Palavras-chave: Poder; Senhorio episcopal; Negociação.

\begin{abstract}
This article analyzes the action of the seigniorial-episcopal power in the tension present in the seigniories territories of the Castilian-Leonese dioceses of Sigüenza, Osma and Tarazona in the middle of the 12th century. Through diplomatic documentation, the negotiating relations between the bishops in the adjustment of the delimitations of their diocesan borders are problematized and the weight that the seigniorial power exercised in the resolution of these conflicts.
\end{abstract}

Keywords: Power; Episcopal Seigniorial; Negotiation.

\section{Introdução}

Entre os séculos XI e XII, percebe-se na configuração territorial da Península Ibérica um expressivo processo de estabelecimento de relações senhoriais 
fundamentadas numa série de negociações entre diversos integrantes da aristocracia cristã medieval e que desaguarão por toda a sociedade, Ihe dando, assim, uma tônica senhorial no desenrolar de sua história. ${ }^{59}$

Sem hierarquizarmos, podemos afirmar que diversos aspectos podem ser elencados para explicar esse fato: o desenrolar da Reconquista; o contato, cada vez maior, entre as monarquias ibéricas e a cúria romana, o que firmará uma via de mão dupla, evidenciando a importância dos pactos pessoais; a restauração de dioceses e o fortalecimento local dos bispos por meio da guerra e da paz; as necessidades do papado, das igrejas e das coroas em se firmarem diante da realidade senhorial, etc. Ou seja, o horizonte que se desenhava em traços firmes na Hispania centro-medieval possibilitou naquele momento um profícuo espaço de conflitos e negociações políticas, tendo defendemos - os senhorios como modus operandi no processo de legitimação das mais variadas forças em choque.

Neste artigo, analisaremos, especificamente, a ação do poder senhorialepiscopal nos tensionamentos entre as dioceses castelhano-leonesas de Sigüenza, Osma e Tarazona, entre os anos de 1135 e 1146. A documentação diplomática deste período é riquíssima em dados e, em se tratando de problematização, ela nos possibilita investigar as características das relações de negociação entre os senhores bispos nos diversos conflitos e ajustes dos seus territórios senhoriais e, também, nas delimitações das fronteiras diocesanas. Ao mesmo tempo, por meio de um estudo atento do que nos chegaram por meio de doações, sentenças e acordos firmados entre os mais diversos senhores, podemos identificar o que denominamos como um tipo de rede de interdependência política entre a Igreja e a Monarquia, na qual ambos participaram de

\footnotetext{
${ }^{59} \mathrm{O}$ processo de senhorização da Península Ibérica, em especial de Castela e Leão, foi sobremaneira debatido durante todo o século XIX e o XX tendo como tônica a feudalização ou não da região. Consequentemente, formaram-se grupos opostos em linhas interpretativas. Para nós, como ficará explicitado em todo nosso artigo, esse é um detalhe que não deve superar o indiscutível aspecto das relações de poder que tiveram no senhorio o ponto fundamental da política praticada na região durante os séculos de XI a XIII. Isso, de fato, se torna latente para as duas principais linhas interpretativas - a de defesa de um feudalismo espanhol e a que a rechaça -, que foi durante essas centúrias que as relações senhoriais tiveram maior visibilidade, sendo o século XII seu ápice. Sobre isso, ainda é de fundamental leitura os textos clássicos de Salvador de Moxó que podem ser encontrados na coletânea: ORTIZ DE VILLAJOS, 2000.
} 
um mútuo e contínuo processo de legitimação e que, no caso abordado neste trabalho, expõe a ação do que temos chamado de poder senhorial-episcopal, elemento este que deu os principais tons à imensa paisagem que se desenhou na tela daquilo que foi a sociedade senhorial ibérica na Idade Média Central.

\section{Para além de uma quimera historiográfica: o senhorio medieval}

Um dos maiores problemas legados aos historiadores é o complexo trabalho de lidar com conceitos que não são contemporâneos aos documentos manuseados, lidos e relidos, sejam aqueles poucos restantes ainda manuscritos ou mesmo as importantes edições críticas presentes em nossas estantes ou em arquivos nos computadores. Alguns termos acabaram sendo cunhados muito depois que a própria realidade - à que eles se referem como nome definidor - se esvaeceu. ${ }^{60}$ Marc Bloch, por exemplo, ao mergulhar no profundo abismo do estudo sobre o feudalismo, afirma, não sem razão de cautela, que "as palavras (...) são como moedas muito usadas, à força de circularem de mão em mão perdem o seu relevo etimológico" (BLOCH, 2015, p. 11).

De fato, o termo feudalismo, criado, ao que tudo indica, no século XVII como um enunciado para definir aquilo que se considerava até então como as típicas relações sociais marcadas por obrigações militares e jurídicas entre senhores e vassalos - ao menos assim se apropriou e defende ainda hoje uma parcela da historiografia institucionalista - é um dos muitos pontos cegos no caminho dos mais variados tipos de historiadores. Ao passo de alguns defenderem seu abandono, frente a sua "inexistência" enquanto substantivo para a Idade Média. Alguns outros o alçaram ao posto de um tipo de sistema social; há também a perspectiva de defendê-lo como um modo de produção;

\footnotetext{
$60 \mathrm{Sim}$, mesmo num mundo tão aficionado pelas relações - não menos importantes - de um mundo virtual, ela, a realidade ainda existe e, consequentemente, mesmo que "como um sonho do historiador", parafraseando Georges Duby, a respeito da "verdade", essa mesma realidade que hoje nos assombra, de certo, assombrou mulheres e homens no passado. Um livro ainda interessante e que esconde interessantes reflexões: Diálogos sobre a Nova História, de Georges Duby e o filósofo Guy Lardreau. É interessante observar um Duby que para muitos não teria sido "teórico" em seus trabalhos, expor ideias que, ainda hoje, parecem soprar um novo ar em tempos tão pesados à nossa profissão.
} 
uma mentalidade; chegando até àqueles que vão além de Bloch e sua sociedade feudal e o definirem como um tipo de civilização. ${ }^{61}$

O jogo retórico, as querelas eruditas, as disputas institucionais e editoriais específicas pouco nos importam, ao menos, para esse nosso estudo. Mas, são fundamentais para confirmar a afirmativa de que, longe de ser um tema empoeirado ou de antiquário, expressões que em suas utilizações argumentativas evidenciam muito mais o comodismo atual dos estudos medievais do que propriamente dito o esforço pelo revisionismo crítico, é necessário dar conta do feudalismo para além do horizonte teórico.$^{62}$ Ora, por todo o seu peso semântico-institucional, como ignorar toda a história que se encontra na bagagem dos debates sobre o feudalismo que vêm se arrastando, no mínimo, por quase dois séculos e meio? Não é coincidência que o drama que marca a trajetória sobre as interpretações das relações senhoriais e toda sua gama de importância na compreensão das mais diversas interpretações sobre as negociações políticas na Idade Média - e da própria História Medieval - estão condenadas ao sumidouro da História do Feudalismo. ${ }^{63}$

Situação um pouco diferente encontramos no caso dos estudos sobre reconquista. Mais uma palavra inexistente no vocabulário medieval, ao menos da maneira como nos foi legada pela historiografia e as fontes tardias por ela estudadas. Diversas pesquisas, já há algum tempo, têm-se aventurado a navegar na conturbada produção acadêmica sobre o termo, não deixando de lado os contextos e embates específicos de cada lugar do discurso.

\footnotetext{
${ }^{61}$ Apenas para citar os comentados entre colegas docentes e discentes nas salas de aula de disciplinas de História Medieval, até onde pudemos identificar em conversas formais e informais no decorrer da nossa trajetória: BASCHET, 2006; BROWN, 1974; DUBY, 1958; GANSHOF, 1976; GUERREAU, 1982; KULA, 1970; REYNOLDS, 1994; SANCHEZ ALBORNOZ, 1979. 3v; VALDEÓN BARUQUE, 1999.

62 Um interessante trabalho de síntese pode ser lido em: ABELS, 2009, p. 1008-1031.

${ }^{63}$ Consideramos que é fundamental - e emergencial - um olhar mais atento sobre o quanto a História do Feudalismo influenciou o que estamos chamando de relações de negociação política tomando o senhorio como seu principal instrumento. Mesmo os mais conhecidos e célebres livros não conseguiram dar conta de tal empreitada. Enquanto esse desafio não for aceito, estaremos longe de iniciar o processo de compreensão mais salutar da importância do senhorio para as sociedades da Roma Tardia, da Idade Média e princípios da Modernidade.
} 
Ao contrário de legar o debate à condição de superado, ano após ano verifica-se o quanto o empreendimento de revisionismo é fundamental para uma melhor compreensão das fontes que foram preservadas e que temos acesso (AYALA MARTÍNEZ, 2007. p. 23-38; BALOUP, 2002, p. 453-480; CUENCA TORIBIO, 2003, p. 695-701; GARCÍA FITZ, 2010; RÍOS SALOMA, 2013; RÍOS SALOMA, 2011; RÍOS SALOMA, 2008; RÍOS SALOMA, 2005, p. 379-414; VANOLI, 2008, p. 1-13).

Diante disso, conceitos e definições para reconquista, sacramentados outrora ou então emudecidos pelas vozes dominantes em determinado período, são resgatados e postos novamente à prova. Ora reafirmados, ora modificados em consonância com aqueles mesmos documentos investigados na poeira do passado.

Não menos profícuo que os acima citados, conscientemente resumidos ao extremo, é o caso do senhorio. Como afirmamos, ele sempre esteve intimamente vinculado ao estudo do feudalismo, e, talvez, tenha sido o que mais sofreu com os reveses ou modismos acadêmicos. Graças ao que bem chamou Alain Guerreau de fratura conceitual, acabou caminhando à sombra do enunciado mais conhecido (GUERREAU, 2002). Afinal, ainda hoje é quase lugar comum encontrarmos os termos sociedade feudal ou, ainda, civilização feudal, enquanto ele permanece à margem, sobrevivendo à luz de estudos que têm buscado classificá-lo destrinchando seus aspectos específicos (ESTEPA DÍEZ; PÉREZ-ALFARO, 2001; SARASA SÁNCHEZ; SERRANO MARTín, 2010). Porém, não deixa de soar contraditório um conhecido manual entre os medievalistas brasileiros, intitulado A civilização feudal: Do ano mil à colonização da América, afirmar que:

Desde que se renuncie a considerar as relações vassálicas o coração da sociedade medieval, como queria a historiografia centrada nos aspectos institucionais e políticos, surge uma polêmica semântica. Mais do que continuar a falar de sociedade feudal, o que parece pôr ênfase sobre o feudo e sobre as instituições da vassalidade que regulamentaram sua transmissão, não seria melhor preferir a noção de sociedade senhorial? O que é certo é que o senhorio é, de fato, a unidade de base, no seio da qual se instaura a relação de dominação e de exploração entre dominantes e dominados (BASCHET, 2006, p. 165). 
Jérôme Baschet parece compreender a validade argumentativa de voltarmos nosso olhar para o senhorio, já que procura deslocar a ênfase da vassalidade para ele e para a relação de dominium que nele se estabelece. ${ }^{64}$ Contudo, o medievalista francês prefere manter-se ainda em harmonia com as duas linhas interpretativas do debate entre senhorio e feudalismo (ou vice-versa), posicionando-se sem posicionar-se: “[...] sobretudo, os termos clássicos sociedade feudal e feudalismo remetem a uma convenção tão solidamente ancorada que é mais fecundo transformar a sua compreensão do que modificar seu nome" (BASCHET, 2006, p. 165).

De todo modo, defendemos que sendo o senhorio um dos elementos de permanência mais impactantes, indo desde a Antiguidade Tardia até, de fato, aos tempos modernos, ${ }^{65}$ ele não só nos possibilita investigar o quanto das relações políticas na Idade Média foram moldadas tendo como pano de fundo um quadro amplo de características, que vão desde a Economia até os arranjos baseados no exercício da Guerra, como também, nos colocar diante da constatação de um complexo emaranhado conceitual que pede urgência de análise, independentemente de ser ou não um sistema, como assim o quiseram tantos historiadores.

Porém, a luta para obter a vitória sobre essa quimera de fundo historiográfico tem sido penosa. Como conceitualizar um enunciado cujas características são tão numerosas e que dividem tantos posicionamentos, cada um em sua trincheira?

Essa dificuldade, Dominique Barthélemy explicitou com a seguinte reflexão:

\footnotetext{
${ }^{64}$ Segundo Alain Guerreau (1998, p. 92), a relação de dominium se define por "una relación social entre dominantes y dominados, en la que los dominantes ejercían simultáneamente un poder sobre lós hombres y un poder sobre las tierras.".

${ }^{65}$ Ver, por exemplo: WICKHAM, 2013. Não significa com esta nossa afirmação que entendemos o senhorio como um elemento a-histórico, ou seja, imutável nas muitas rupturas e continuidades da História em seu movimento. Contudo, em experiências recentes baseadas em investigações ao lado de colegas docentes do Programa de Pós-Graduação em História da Universidade Federal de Sergipe - como o Prof. Dr. Carlos de Oliveira Malaquias - temos observado que o senhorio e as relações de força e poder que o envolvem são aspectos profícuos para a tentativa de compreensão de diversas dinâmicas históricas globais do passado mais longínquo com o mais próximo. Nossos debates serão expostos na disciplina optativa Tópicos Especiais em História e Poder do PROHIS-UFS.
} 
Vários volumes seriam insuficientes para a análise historiográfica daquilo que os medievalistas chamaram o "senhorio", um tipo de poder não estatal, próximo, rude e privatizado. A própria palavra dominium, as de sua família, não tem nenhuma conotação particular nas fontes medievais, e é normal que o historiador elabore o conceito, apresentando-o em seguida para discussão (BARTHÉLEMY, 2002, p. 465).

De fato, é difícil não concordar quando ele afirma que senhorio e seu conceito se aplicam a diversos objetos históricos, além de conseguir ser um leque tamanho de coisas: domínio rural que ditará as relações entre os homens ao se aproximarem de seu chefe ou o poder déspota de um castelão; pode ainda representar as relações de homem a homem, com suas negociações e personalismos etc. (BARTHÉLEMY, 2002, p. 465). Podemos ir um pouco mais longe e considerá-lo como direito de cobrança de passagem, uma exploração de tipo econômico, etc. Uma possibilidade de definição de conceito bastante utilizada, como é possível verificar nos mais variados estudos, é pensá-lo como tipo de poder de mando exercido sobre homens e terras, mesmo que Barthélemy e outros sejam um tanto reticentes quanto a essa definição, mas que de certa forma abarca tudo o que foi listado acima.

Seja como for, o senhorio é um dado histórico e, por isso mesmo, não deve ser ignorado. Ele é esse espaço no qual as tessituras do agir político e a ossatura institucional são moldadas pelos interesses mais variados dos atores sociais em vias de choque, se organizando, desorganizando e reorganizando conforme as negociações em curso.

O impasse de mantê-lo como um conceito aberto e, deste modo, nos sujeitarmos ao risco de ver nele tudo e nada, como um espectro presente em todo lugar, quase como uma categoria vazia, mas transbordante; ou fechá-lo numa definição de tipo modelar, como uma peça que consegue ser encaixada numa construção teórico-metodológica pré-moldada, pode nos levar a contrassensos de não perceber no senhorio este espaço tão amplo para os constantes arranjos sociais.

Ou seja, compreendemos que ele é um meio fundamental para a concretização das relações de poder encontradas nas mais variadas situações de tensionamentos político-sociais. Para nós, nos aproximando em muito da ideia guerreauniana de dominium, o senhorio é um poder exercido por direito de conquista ou mesmo por 
recebimento através de outrem, seja sobre uma terra ou não, incluindo aí seus habitantes. Por isso mesmo ele é um elemento essencial para a legitimação dos atores em posição de mando em suas constantes vias de conflito, os mesmos que percebiam nele um mecanismo importante para negociações e alianças. E aqui certamente ele toma seu formato mais delicado para a análise histórica: Ele está sim intimamente vinculado, como o quiseram medievalistas como Bloch, Duby e mesmo Alain Guerreau, ao agrário, na verdade, grosso modo, à terra, e suas etéreas fronteiras entre o campo e a cidade. Ou seja, o senhorio é, de fato, um poder que age sobre o material, fincando nele as suas regras e interesses, conseguindo se mover sobre bens móveis e imóveis que irão definir muito bem o curso das negociações entre os interessados em dominar, o máximo possível, a sociedade. Ele estará ali constantemente, e cabe a nós percebê-lo, mesmo quando os documentos tardo antigos e medievais não explicitá-lo, como assim o quis Alain Guerreau, em suas complexas teias narrativas com o seu mais constante enunciado, o dominium.

Defendemos que, por meio desta perspectiva, o senhorio será sempre esse caminho de afirmação das forças político-institucionais que marcaram as relações de poder na Idade Média: o papado, as igrejas locais, as monarquias, o campesinato etc. Deste modo, sendo parte integrante das ações políticas de negociações que explicitarão diversos tipos de interdependência, o senhorio desmembrar-se-á sempre como uma peça-chave e indispensável para os poderes específicos no agir de tais forças, tomando como área de ação os territórios e, consequentemente, suas fronteiras.

É necessário frisar que temos entendido poder como sinônimo das tensas relações que ocorrem dentro de algumas organizações sociais, na qual os interesses específicos são fomentados ao mesmo tempo em que, dialeticamente, reincidem e transformam um universo mais amplo de interesses e propósitos socialmente partilhados. Com esta definição, alcançamos, pelo menos, duas vantagens: 1) reconhecer a especificidade de um campo de poder demarcado político e institucionalmente pela existência de instâncias como, por exemplo, o papado, as monarquias e as igrejas diocesanas e, ao mesmo tempo, tal conceitualização indica que este campo só alcança sentido se compreendido nas tensões decorrentes da condição 
senhorial dos envolvidos, uma vez que não podemos ignorar que eram possuidores de senhorios. Assim, 2) o laço social que chamamos de poder é a assimetria de posições sociais e diferença de interesses, ou seja, uma arena aberta ao conflito e à luta. Entretanto, pressupõe, ao mesmo tempo, cooperação, solidariedade, envolvimento e aproximação. Assim:

O senhorio é, provavelmente, um dos primeiros laços sociais que vem à mente quando pensamos sobre as solidariedades sociais medievais. Trata-se de um fenômeno complexo, abrangendo uma grande variedade de relacionamentos. Estes vão desde íntimos e diretos laços de mestre e seus retentores domésticos para as altamente formais - e muitas vezes emocionalmente distantes - relações de um grande príncipe e seus súditos (GIVEN, 1997, p.169 e 170).

Essa noção de poder se ajusta às relações estabelecidas entre as instâncias supracitadas anteriormente, colocando o senhorio como centro do debate que norteou as relações de negociação que, para nós, evidenciaram a interdependência entre elas.

Por fim, teórico-metodologicamente, perceber poder e senhorio da maneira como defendemos, permite, mesmo dentro de uma postura totalizante de Sociedade Senhorial, ainda assim trabalhar com especificidades de poderes que se consolidam graças a sua existência, como, por exemplo, o poder senhorial-monárquico, senhorialpapal, senhorial-episcopal etc. ${ }^{66}$

Para nós, por uma série de questões particulares da documentação que analisaremos a seguir, tem sido interessante nos centrarmos no chamado poder senhorial-episcopal que, nada mais é, do que a ação combinada da legitimidade senhorial nas mãos dos bispos. Possibilitando a eles um manejo e posicionamento políticos - nem sempre confortáveis - nos tensionamentos inerentes à Sociedade Senhorial.

O que afirmamos é: o poder senhorial-episcopal é o modus operandi dos processos de negociação presentes e necessários naquele período, cuja legitimidade do

\footnotetext{
${ }^{66}$ Todas essas questões estão explicitadas em ALVARO, 2013.
} 
governo episcopal estava em constante bombardeamento de forças (papado, monarquias e esferas, das mais diversas, da aristocracia senhorial). Ele salienta, também, o quanto isso estabelecia uma interdependência de cunho horizontal entre as instâncias, diferentemente do que muitas vezes deixa a entender alguns ramos da historiografia.

Todo esse contínuo ir e vir de forças encontra na doação e na conquista de direitos de ocupação territorial, através do senhorio, o principal alicerce para que os senhores bispos se firmem em sua autoridade, aspecto único e basilar para a manutenção e expansão de sua influência local e regional. ${ }^{67} \mathrm{Ou}$ seja, nessa constante variação entre quem manda e quem obedece encontrava-se, justamente, a prerrogativa do poder senhorial-episcopal.

É interessante observar que esse fenômeno não se restringe somente às relações episcopais. Em uma pertinente análise cronística das relações de negociação entre a monarquia e as forças nobiliárquicas, o medievalista Julio Escalona Monge demonstra que o que ditava a pauta política naquelas centúrias era justamente uma incessante busca por alianças que, ao mesmo tempo, eram desfeitas e refeitas. Sua constatação rompe com uma noção tradicional da historiografia no que diz respeito as questões acerca do chamado "modelo francês" (ver: ESCALONA MONGE, 2004, p. 102 e 103).

Demonstraremos a seguir - como temos feito insistentemente em nossas pesquisas - como a ação do poder senhorial-episcopal nos tensionamentos presentes, ao menos, nos territórios senhoriais das dioceses castelhano-leonesas de Sigüenza, Osma e Tarazona, em meados do século XII, influenciou nas negociações a respeito da resolução das querelas acerca das delimitações das fronteiras diocesanas destes senhorios episcopais.

\footnotetext{
${ }^{67} \mathrm{Em}$ alguns casos, o raio de ação de um senhor bispo extravasava as fronteiras diocesanas, criando, assim, uma situação complexa e singular, na qual é possível testemunhar bispos exercendo o poder senhorial-episcopal em dioceses que não a sua, ou seja, senhorializando territórios diocesanos de sua sede.
} 


\section{Disputas episcopais de fundo senhoriais: Sigüenza, Osma e Tarazona}

A política episcopal e monárquica em finais do século XI e durante todo o século XII tiveram uma característica curiosa na Península Ibérica e, de fato, isso pode ser observado em todo o território peninsular: a ligação entre os senhores bispos, monarcas e mesmo com as forças aristocráticas locais seguiu uma regra clara de negociações fundamentadas em pressupostos de contrapartidas entre eles.

A monarquia de Castela, sob o governo de Alfonso VII, o Imperador, desde cedo percebeu a necessidade de promessas, de vínculos e, sem temer possíveis perdas, de disputas - fossem elas internas ou externas. ${ }^{68}$

Dito isso, não é difícil nos depararmos com interessantes documentos de cunho diplomático que escondem por trás das frias fórmulas de doações toda uma rede de interdependência que marcou o período, assim como as mais variadas disputas que lhe serviram como fonte de origem.

O caso de análise que trazemos à tona, é um dos muitos que acabaram silenciados pela historiografia institucionalista tradicional ou que, simplesmente, viram neles - quando viram - exemplos de confirmação de uma não-feudalização ou de uma extrema senhorização ibérica na Idade Média. Seja qual for o posicionamento, um ou outro sempre estiveram cobertos pelas nuvens espessas do século XIX.

Sigüenza, Osma e Tarazona fazem parte de uma série de dioceses que no decorrer do século XII estavam numa constante busca pela consolidação do poder senhorial-episcopal ou por sua manutenção. E neste jogo de negociações, a busca pela demarcação de suas fronteiras era fundamental.

Para analisarmos como se deram os entraves entre esses bispados, utilizaremos, aproximadamente, seis documentos emitidos num espaço de praticamente uma década: uma carta do papa Inocêncio II em resposta ao monarca Alfonso VII, o Imperador (1136); uma sentença proferida pelo Cardeal Guido, Legado papal (1136); uma carta de confirmação de acordo emitida por Alfonso VII, o Imperador (1136); duas

\footnotetext{
${ }^{68}$ Um exemplo interessante pode ser lido em: FERNÁNDEZ CONDE, 2007, p. 67-87.
} 
bulas de Inocêncio II (1136 e 1139) e finalmente, outra bula, porém, emitida por Eugênio III (1146). ${ }^{69}$ Outros documentos diplomáticos também foram utilizados, contudo, a quesito de cotejamento e não são efetivamente reproduzidos no corpo do texto do presente artigo.

Durante o gradual processo de legitimação dos senhorios episcopais de Sigüenza, Osma e Tarazona, nós verificamos situações de tensões com a monarquia castelhanoleonesa. Contudo, por meio da negociação e dos laços firmados por meio de uma interdependência entre as duas instâncias - as igrejas e a coroa de Castela -, também foi possível identificar que as doações realizadas pela monarquia possibilitaram o fortalecimento de ambas as partes, já que, naquele período, este era um dos principais problemas tanto para Alfonso VII como para os bispos Bernardo de Sigüenza, Bernardo de Osma e Michel de Tarazona. ${ }^{70}$

A documentação que temos em mãos não nos permite ter toda a segurança para estabelecer os limites dos senhorios episcopais em questão, uma vez que as fronteiras medievais sofriam constantemente modificações frente aos muitos processos de cunho militar (ESTEPA DÍEZ, 2006, p. 15-86; GONZÁLEZ GONZÁLEZ, 1982, p. 411-424; SABATÉ I CURULL, 2007, p. 47-94 e SOTO RÁBANOS, 1997, p. 213-220). Porém, de imediato ressaltamos que, para nós, tais litígios foram além de conflitos tipicamente diocesanos e devem ser vistos como tensões entre senhorios episcopais negociando pela legitimidade de sua autoridade nos territórios recém adquiridos por meio de doações ou de aquisições fundamentadas em conquistas militares próprias (AYALA MARTíNEZ, 2009, p. 513-529; BLÁZQUEZ GARBAJOSA, 1985, p. 35-42 e SEVILLA MUÑOZ, 1985, 4356). Não podemos ignorar que o momento em que tais querelas vieram à tona, a monarquia castelhano-leonesa estava entrando em um momento de condição mais propícia politicamente: Alfonso VII já não tinha à sua sombra seu antigo padrasto,

\footnotetext{
${ }^{69}$ Tais documentos foram publicados em 2019, pela EDUFBA, graças ao Edital PROPCI-PROPG/UFBA 04/2013 PRODOC/UFBA, numa edição bilíngue latim-português intitulada Documentação Diplomática da Diocese de Sigüenza entre 1124 e 1151, organizada pelos historiadores Bruno Gonçalves Alvaro, da Universidade Federal de Sergipe e por Marcelo Pereira Lima, da Universidade Federal da Bahia.

${ }^{70}$ Sobre as relações entre a monarquia e episcopados indicamos o interessante e ainda indispensável estudo: NIETO SORIA, 1982, p. 197-218.
} 
Alfonso, o Batalhador; havia sufocado as rebeliões aristocráticas internas e, apesar de ter perdido Portugal para seu primo Alfonso Henríquez, conseguiu, mal ou bem, manter a Galiza sob seu cetro. ${ }^{71}$ Além disso, iniciou sua nova política de afirmação imperial.

Ou seja, foi neste contexto, como bem demonstrou Salvador de Moxó, quando ocorria o ápice da senhorização em Castela e Leão, iniciado nos anos finais do século XI (ORTIZ DE VILLAJOS, 2000, p. 141), que estes senhorios episcopais colocam-se diante da extrema necessidade de demarcar suas áreas de influência e, para isso, como veremos mais a seguir, muita tinta foi derramada nos pergaminhos e, mesmo o papado se viu na posição de ter que interferir nessas querelas, enquanto, coincidentemente, a monarquia castelhano-leonesa, com seu sonho imperial, tentava dar amostras de ter, ao menos, um mínimo respeito aos representantes do Trono de São Pedro.

A disputa territorial entre Sigüenza, Tarazona e Osma partiu de uma importante doação monárquica de Alfonso VII: a cidade de Sória. ${ }^{72}$ Tudo indica que esta querela foi se arrastando e com o passar dos anos tornando-se cada vez mais complexa, a ponto de testemunharmos a intervenção papal por meio de seu Legado Pontifício que, neste caso, nos parece ter agido em sintonia com o representante de Pedro.

Quando Alfonso VII doa, em 1127, ao bispo de Sigüenza a cidade de Sória, ela não era nada além do que um território recentemente devastado, deste modo, o que o bispo tinha em mãos era, na verdade, mais um projeto de reconstrução do que efetivamente uma fonte imediata de sustento senhorial. ${ }^{73} \mathrm{O}$ conteúdo da doação possui, inclusive, um teor de concessões de direitos que, paradoxalmente, o prelado seguntino não havia como desfrutar. Mesmo as salinas régias de Medinaceli (também

\footnotetext{
${ }^{71}$ É primordial relembrar todo o poderio do principal senhor dos territórios galegos, o bispo Diego Gelmírez. Interessantes trabalhos vêm sendo publicados sobre o episcopado gelmirenze por Jordano Viçose e cuja pesquisa tem focado em Santiago de Compostela, cujos episcopados uma das maiores parcelas de senhorios da Idade Média Central Ibérica.

${ }^{72}$ Cf. Documento Núm. V - Ano 1127 (ALVARO; LIMA, 2019, p. 43-45) e Documento Núm. VII - Ano 1135 - Junho (ALVARO; LIMA, 2019, p. 50-53).

${ }^{73}$ Cf. Documento Núm. V - Ano 1127 (ALVARO; LIMA, 2019, p. 43-45).
} 
traduzida por Medina),${ }^{74}$ doadas a ele, estavam destruídas. O que Alfonso VII faz neste privilégio era eximir-se ele mesmo de organizar aquela região, tanto que suas principais ordenanças recaem sobre o bispo seguntino como obrigações tipicamente senhoriais, como, por exemplo, neste caso específico, reedificar as salinas e os moinhos para então possuí-los.

Em todo caso, como é possível acompanhar pelos direitos e privilégios que vão sendo concedidos no decorrer dos anos, Bernardo de Sigüenza parece ter conseguido reestruturar a região sob sua influência e ter exercido seu poder senhorial-episcopal não sem alguns problemas. E, certamente, o entrave mais complexo de todos foram as queixas dos bispos de Osma e Tarazona a respeito das definições de limites entre as fronteiras de suas dioceses e a de Sigüenza. O mais provável foi que a expansão do senhorio seguntino tenha se chocado com a própria organização senhorial-episcopal de Osma e Tarazona. ${ }^{75}$ Não podemos ignorar que quando Alfonso VII concedeu à Sigüenza, em 1135, ou seja, pouco antes das queixas dos supracitados bispados, por exemplo, a décima parte de todo o rendimento real juntamente com a igreja de Santa Maria de Bolmajo e todos os seus limites, pareceu ignorar a situação diocesana do local.

Diante da situação que era, provavelmente, insustentável, os bispados que se viram prejudicados recorreram a uma ajuda externa, no caso, o papado. Consideramos que isso nos revela dois aspectos: Alfonso VII se mantinha na busca por uma neutralidade frente aos acontecimentos para não prejudicar o processo de legitimação do Império, mas, ainda assim, parecia estar mais inclinado à causa seguntina e, consequentemente, era visto pelos bispos de Osma e Tarazona como aliado da diocese rival. De qualquer maneira, o litígio se iniciou justamente com o seu processo de doações ao bispo de Sigüenza e analisando as entrelinhas, parece-nos que o monarca castelhano-leonês, procurando fazer jus de sua autoridade e do poder monárquico e, estrategicamente se ver a salvo dos consequentes problemas que uma política de

\footnotetext{
${ }^{74}$ Nesse caso, não confundir com famosa cidade de Medina, na Península Arábica, e que marca o processo de início do domínio maometano em 622 da nossa Era, após sua fuga de Meca.

${ }^{75}$ Sobre as dioceses de Osma e Tarazona ver: ANIZ IRIARTE, 2000, p. 373-416; MARTíN VISO, 1999, p. 151190; PECES RATA, 2005, p. 547-552; TAMBO MOROS, 2006, p. 89-112, entre outros.
} 
vínculos lhe custava, enviou cartas ao papa Inocêncio II, contudo, intercedendo por Bernardo de Sigüenza, o que, após algumas comunicações foi respondido pelo Pontífice romano:

Inocêncio, bispo e servo dos servos de Deus, ao caríssimo filho em Cristo Alfonso, ilustre e glorioso rei das Espanhas, saudação e benção apostólica. Tendo examinado o mérito de suas cartas em favor do nosso venerável irmão Bernardo, bispo de Sigüenza, louvamos ao Senhor a tua solicitude, pois, como príncipe bom e justo, amas as sacrossantas igrejas e procuras reintegrá-las aos seus direitos. Assim, nós, atendendo às suas súplicas, estamos determinados a deixar inteiramente nas mãos do nosso amado filho Guido, diácono cardeal da Santa Igreja Romana, legado apostólico de nossa Sede, a cidade de Sória e que os ofícios episcopais não sejam exercidos ao mesmo tempo pelos nossos irmãos Miguel, bispo de Tarazona, e Bernardo, bispo de Osma, e mandamos pelos escritos apostólicos que não se intrometam nos rendimentos episcopais daquele mesmo lugar até que o referido legado, a quem compete àquela paróquia, resolva [a contenda] com teu conselho e dos outros, [e] com a ajuda de Deus. Diante disso, certamente, consideramos a tua excelência para interceder de forma precisa com o nosso irmão tanto nesta quanto em outras casos [mais dignos de atenção] que tenhas comandado; assim, também desejamos tentar no presente pôr à prova essa questão, de modo que seja concedido livremente o castelo de Santiuste na presença do venerável Humberto, então presbítero cardeal [e] legado da Sede Apostólico, e dos bispos e abades, no concílio da sua Igreja de Carrión, [e] que tu remetas ao nosso mesmo irmão; e que, a partir desse momento, concedeste piedosamente a ele os esperados bens, para que procures sem demora efetivamente realizar, assim como o nosso mesmo irmão sinta serem úteis as nossas súplicas junto a ti; e [que] tua devoção consiga receber as premiações eternas para sempre. $E$ isso deves fazer tanto por boa vontade quanto pela mencionada pessoa do nosso irmão [o qual] sabemos ser fiel e devoto a ti, e [que] trabalhou muito em prol da sua honra e proveito. Datado de Pisa na Sexta Kalendas de Janeiro (27 de Dezembro) (Documento Núm. XII. ALVARO; LIMA, 2019, p. 73).

Como podemos perceber, o papado procurou dirimir sua responsabilidade e, ao mesmo tempo, anular a insistência monárquica sobre o litígio em questão, depositando sobre seu legado, o cardeal Guido, a responsabilidade de sanar a querela episcopal entre Bernardo de Sigüenza e os bispos de Bernardo de Osma e Michel de Tarazona. Mas, ao mesmo tempo, Inocêncio II, também ele um senhor episcopal, ${ }^{76}$ não deixou de buscar a legitimação por meio do exercício da autoridade papal, que, para nós, evidencia-se

\footnotetext{
${ }^{76}$ Algumas considerações sobre a condição senhorial do papado na Idade Média podem ser encontradas no ainda pertinente estudo $A$ sociedade feudal de Marc Bloch. Indicamos ainda os trabalhos do historiador Leandro Duarte Rust, da Universidade de Brasília, sobretudo: RUST, 2018 e RUST, 2011.
} 
como reconhecida, à medida que tanto os bispos em questão como o monarca recorreram à sua intervenção.

Um olhar superficial deixaria passar a tensão senhorial-episcopal expressa na resposta papal, principalmente por sua decisão de que os ofícios e rendimentos episcopais, até a decisão do cardeal Guido, não deveriam ser exercidos. Ora, isso não é de surpreender, afinal, o fenômeno senhorial-episcopal não pressupõe ações separadas ou específicas entre a função de bispo e a de senhor. Aliás, essa "fusão" é um dos principais aspectos de ação do poder senhorial-episcopal.

Diante do posicionamento monárquico reclamando soluções, principalmente favoráveis ao bispo de sua predileção, Inocêncio II relembra à Alfonso VII, por fim, que aquele mesmo bispo ainda aguardava a entrega do castelo de Santiuste, doação feita pelo rei em $1129^{77}$ e que até aquele momento ainda não havia sido sacramentada. 0 pontífice romano ainda ressalta a extrema fidelidade de Bernardo de Sigüenza ao monarca castelhano-leonês. Isso nos confirma que, apesar da tentativa de neutralidade, aparentemente havia uma predileção da solução deste caso a favor do senhorio episcopal de Sigüenza, ao menos, por parte do monarca castelhano-leonês.

A resolução do litígio recaiu sobre a responsabilidade do cardeal Guido, Legado Pontifício presente na Península Ibérica naquele momento. Não cabe aqui analisar as redes às quais ele esteve vinculado, o que ampliaria demasiadamente nosso foco principal nesse breve artigo. ${ }^{78}$ Porém, ao que tudo indica, após o Concílio de Burgos, o Legado definiu os novos limites entre as dioceses de Sigüenza, Osma e Tarazona fundamentando-se na División ó Hitación del Rey Wamba. ${ }^{79}$ Em documento direcionado a Bernardo de Sigüenza, o cardeal sentenciou que:

\footnotetext{
77 Cf. Documento Núm. II - Ano 1129 - 13 de Julho (ALVARO; LIMA, 2019, p. 32-34).

${ }^{78}$ Guido aparece documentado, entre 1136 e 1137, trocando cartas com o arcebispo de Compostela, Diego Gelmírez. Cf. HISTORIA COMPOSTELANA. Introducción, traducción, notas y índices de Emma Falque Rey. Madrid: Akal, 1994. p. 588 e 589.

79 Documento em que o rei Wamba criou dioceses e estabeleceu os limites dos bispados na Alta Idade Média. Para grande parte da historiografia trata-se de uma falsificação do século XII, empreendida pelo bispo de Oviedo, Pelayo. Porém, essa possível "falsificação" de Pelágio foi bastante invocada, durante a Idade Média Central, para "solucionar" conflitos de limítrofes diocesanos. Cf. VILLAR GARCíA, 1987, p. 385-400. Ver ainda: GONZÁLEZ GARCIA, 1987, p. 263-291. Por fim, a indispensável leitura de BLAZQUEZ,
} 
Guido, cardeal diácono e legado da Santa Igreja Romana, para o venerável irmão B., bispo de Sigüenza, saudações [Ele] ocupou-se da dissensão entre ti e os nossos veneráveis irmãos, os bispos Miguel de Tarazona e Bertrando de Osma, diante da grave controvérsia da cidade de Sória. E certamente demonstra a fronteira da própria cidade, como também a antiga divisão dos bispados, tanto para as igrejas de Sigüenza quanto para Osma e Tarazona, [que] geralmente diz respeito aos que eram vistos. Nós, então, para a paz dos que mais sofrem, com o conselho dos homens do Imperador da Espanha, Alfonso, dos arcebispos, dos bispos, dos abades e dos outros religiosos e dos homens sábios, que se reuniram no concílio de Burgos, desta forma, construímos pela autoridade do Senhor a concórdia entre ti e os próprios [bispos]. De modo que, sem dúvida, destas propriedades que tinham pertencido à Igreja de Sigüenza, [que] a Igreja de Tarazona possua Calatayud, Borovia, Alcazar com todos os seus territórios do entorno das Villas. A Igreja Matriz de Calatayud com todas as suas heranças e herdades, as quais, no mesmo lugar, comprou, distinguirás Olvega, Villa Feliz, que está entre Calatayud e Daroca, a Villa, que é conhecida como Salas próximo de Olvega, reservastes nomeadamente dois castelos para a propriedade da Igreja de Sigüenza. Evidentemente, Deza, que fica localizada entre Calatayud, Almazán e Ariza, entre Calatayud e Medinaceli. Com toda a certeza, a ti, caríssimo irmão em Deus, bispo Bernardo, é concedido de iure a Igreja de Osma [e] Ayllón com todas as regiões que estiver em seu entorno e as herdades, as quais o bispo possuía nos mesmos lugares. Aguisejo, Castelo de Galve, o meio da aldeia, que é conhecida como Liceras, Caracena, com todas as suas aldeias e com dois mosteiros de San Salvador e Santa Maria de Termes. Vadorey, Aguilera, Berlanga, com todas as suas regiões fronteiriças e com o mosteiro de Santo Baudilio, Balamuza, Barca e, além disso, Almazán, com todas as suas regiões, sobre as quais o bispo de Osma tinha feito sua reclamação. Além disso, ao mesmo bispo de Osma, concedemos toda a Sória com todas as suas regiões das quais a controvérsia tinha sido deflagrada e o mosteiro de Santa Maria de Bolmajo e os dízimos reais da mesma Villa, que juridicamente pertencia à Igreja de Sigüenza; portanto, por este acordo entre vos, que intercede, pela divina clemência, a estabilidade a partir da autoridade da Santa Igreja Romana, que a nós é concedida sob a autoridade do Senhor a estabelecer as divisões dos limites paroquianos, confirmamos e determinamos a permanecer válido perpetuamente pelos tempos (Documento Núm. X - Ano 1136 (?). ALVARO; LIMA, 2019, p. 65-66).

A sentença de Guido diminuiu claramente o alcance territorial do episcopado seguntino e ao mesmo tempo dificultou a ação do seu poder senhorial-episcopal, já que, em tese, retirou alguns privilégios jurisdicionais como, por exemplo, os dízimos reais que haviam sido outorgados por Alfonso VII ao bispo de Sigüenza. Contudo, isso não

1907, p. 67-107. Nesse extenso artigo, Antonio Blazquez refuta veementemente a tese de Enrique Flórez de que o documento trata-se de uma falsificação. O mesmo disponibiliza, também, o documento atribuído a Wamba. Indicamos também o artigo de GONZALEZ GARCIA, 1993, p. 173-215. 
significou que o litígio se resolveu prontamente. Mesmo tendo Alfonso VII confirmado, ao lado de nomes como Diego Gelmírez e Raimundo de Toledo, ${ }^{80}$ o que o cardeal decidiu "a partir da autoridade da Santa Igreja Romana", este conflito se arrastaria ainda por alguns anos. O que para nós se explica graças a uma bula papal de Inocêncio II, datada de 1138 , em que o papado, após ter aprovado a sentença dada pelo cardeal Guido, ampliou um pouco mais o que ele havia definido, depositando nas mãos de Bernardo de Sigüenza e seus sucessores na sede de Sigüenza a posse de alguns castelos. ${ }^{81}$ Inferimos que isso tenha se dado a partir de algum tipo de contestação do bispo seguntino que, como foi possível observar, perdeu substancialmente seus privilégios e territórios para Tarazona e, principalmente, para Osma. Ou seja, o tema em questão recorrentemente voltaria à pauta das preocupações papais e mesmo da monarquia.

O conteúdo desta bula de Inocêncio II apresenta consistentes discrepâncias com o que foi possível ler na sentença de Guido e a confirmação de Alfonso VII, em $1136 .{ }^{82}$ De início, o bispo de Roma deixa claro dois aspectos importantes: ele fala em nome da causa de Bernardo de Sigüenza sobre o que foi decidido a respeito da cidade de Sória, o que nos leva a crer que o bispo seguntino "recorreu" à sentença do Legado Pontifício. Em seguida, ele basicamente corrobora com toda a decisão do cardeal Guido no que diz respeito aos limites estabelecidos e o que pertencia a quem, ratificando os limites e os direitos garantidos por Osma e Tarazona. Mas é justamente nessa altura da bula que o pontífice romano insere um fato novo, que não consta nos dois documentos de 1136 : "Reservais, sem dúvida, os dois castelos para a propriedade da Igreja de Sigüenza. A

\footnotetext{
${ }^{80}$ Cf. Documento Núm. XI - Ano 1136 (ALVARO; LIMA, 2019, p. 67-71) É interessante perceber que, apesar de reconhecer a sentença do Legado Pontifício, Alfonso VII procura, em sua carta de confirmação, dividir a autoridade com o papa: "Em nome da santa e indivisível trindade, do Pai, do Filho e também do Espírito Santo, eu, Alfonso, pela graça de Deus, imperador da Espanha, por causa das diferentes discórdias que possam ter ocorrido entre os bispos de meu reino sobre as divisões dos bispados e dos limites paroquiais, até mesmo para o senhor papa Inocêncio, ordenei ao bispo de Sigüenza e ao de Ourense, como também a Don Guido, cardeal da Santa Igreja Romana, para que não se negasse a lançar [paz], em nossas regiões sob a autoridade da Igreja Romana, sob minha anuência, [e para que] possa pôr o fim a tanta dissensão e impor a concórdia; [e] que [isso] permaneça firme e indissolúvel para todos os tempos" (p. 69).

${ }^{81}$ Cf. Documento Núm. XIV - Ano 1138 - 6 de Março (ALVARO; LIMA, 2019, p. 77-83).

82 O conteúdo dos dois documentos, praticamente, não difere em nada.
} 
saber, Deza, entre Calatayud e Almazán e Fariza, entre Calatayud e Medina"

(Documento Núm. XIV - Ano 1138 - 6 de Março. ALVARO; LIMA, 2019, p. 80 e 81).

Por fim, mesmo mantendo toda decisão de seu Legado, Inocêncio II acabou

restituindo/mantendo ao senhorio episcopal de Sigüenza sua presença dentro dos limites do senhorio episcopal de Osma:

[...] Então, que todas as coisas que foram instituídas pelo nosso filho Guido, corroboramos pela fortaleza de nosso favor. Qualquer uma das anteriores possessões [e] qualquer bem que a Igreja de Sigüenza justa e canonicamente possui no presente ou no futuro pela concessão pontifícia, pela liberalidade dos reis ou príncipes, do dízimo dos fiéis ou dos outros justos modos, [que] Deus propiciou e [que se] poderá adquirir - permaneçam firmes e puros a ti e aos teus sucessores, nos quais estes próprios que foram designados pelos vocábulos Medina, como também, Molina, Santiusti, Atienza, ambos os castejones com suas propriedades. Igualmente, a décima parte dos rendimentos reais de todo o episcopado; as salinas, os moinhos e também o castelo de Serone, com todas as áreas do seu entorno. Assim, distinguimos que nenhum homem intente perturbar o direito da citada Igreja de Sigüenza sobre esta nossa concessão e confirmação ou [nem procure] destruir suas possessões, reter ou diminuir as oferendas ou fustigar com quaisquer moléstias. Mas que todas as coisas sejam conservadas intactas, daquelas, cujos usos benéficos são concedidos para o governo e sustento. Se, certamente, no futuro, alguma pessoa eclesiástica ou secular, conhecendo estas páginas de nossas constituições, [e com] uma segunda ou terceira advertência, ousar com imprudência vir atentar contra ela, perca o poder e a honra de sua dignidade e [seja] condenado pelo juízo divino se souber da existência sobre a iniquidade perpetrada e pelo santíssimo corpo e sangue de Deus e do nosso Senhor Redentor Jesus Cristo, faça-o inimigo e, no Juízo Final, subjugue com a distribuição da vingança. [E que] também por todos os seus direitos do lugar haja a paz do nosso Senhor Jesus Cristo até o ponto em que se perceba o fruto das boas ações - e encontrem com a distribuição da justiça as recompensas da paz eterna. Amém, Amém, Amém (Documento Núm. XIV - Ano 1138 - de Março. ALVARO; LIMA, 2019, p. 81 e 82).

Como pudemos observar, isso manteve a presença senhorial-episcopal seguntina no território, o que certamente desencadeou novos conflitos.

Sem termos a exatidão de uma data, mas, possivelmente, há de ser o ano 1139, Inocêncio II escreveu a Bernardo, bispo de Sigüenza, comentando a decisão do cardeal Guido e, ao mesmo tempo, tratando de questões conciliares com o prelado seguntino: 
celebramos um concílio em Roma, sob o favor de Deus, com patriarcas de diferentes províncias, arcebispos, bispos, abades, [e] outros homens religiosos e sábios, [que] apresentaste à nossa presença os que ameaçam a Santa Igreja de Deus, para que pudéssemos aconselhar a ti e aos outros irmãos. Uma vez que, certamente, também afirmastes não poder estar presente neste mesmo concílio, em função de certas razões que são um obstáculo a ti, concedemos por benção apostólica a ti este mesmo [concílio] e sustentamos com equanimidade a tua ausência. Confirmamos também o acordo que tu tomaste conhecimento por tua dileção entre ti e os veneráveis nossos irmãos bispos Miguel de Tarazona e Bernardo de Osma, por mão do nosso caríssimo filho, Guido, cardeal diácono, naquele momento feito legado da sede apostólica pela apostólica autoridade, e comunhamos pelo apostólico privilégio. Do mesmo modo, impomos a partir deste momento o perpetuo silêncio por autoridade apostólica à Pascual, cônego de Osma, que [foi] contra essas palavras firmadas em plenária sinodal. Datado em Latrão, aos XV dias das calendas de Maio (17 de Abril) (Documento Núm. XII. ALVARO; LIMA, 2019, p. 73).

Como afirmamos, nos parece que a concórdia ainda surtia problemas entre dois dos senhorios episcopais castelhanos (Sigüenza e Osma). Tanto que Inocêncio II impõe o silêncio a um cônego da Igreja de Osma que, aparentemente, não concordou com o que foi definido, o que, de fato, ao lermos a aprovação e confirmação do papa, acabou favorecendo o senhorio episcopal seguntino.

Por outro lado, Bernardo de Sigüenza nos parece não ter podido participar do concílio, que acreditamos ter sido o Lataranense II, em 1139, segundo o pontífice romano, em função de certas razões que foram um obstáculo ao bispo seguntino. Tudo indica que se tratava ainda, em parte, das questões de limites entre seu senhorio e os de Osma, o que não o permitia se ausentar durante muito tempo de seu senhorio episcopal temendo o risco de investidas militares de seu rival osmense. ${ }^{83}$ Ao mesmo tempo, os resultados obtidos pelo bispo seguntino nos levam a defender que suas relações com o papado de Inocêncio II eram frutíferas, a ponto de conseguir reverter uma situação de prejuízo em manutenção de importantes direitos senhoriais, ao mesmo

\footnotetext{
${ }^{83} \mathrm{~A}$ sentença do cardeal Guido e a bula de aprovação emitida por Inocêncio II ainda se mantiveram em conteúdo sem modificações no ano de 1146 em documento emitido pelo Papa Eugênio III. Isso nos permite inferir que os litígios senhoriais episcopais entre Osma e Sigüenza ainda estavam acesos na primeira metade do século XII. Cf. Documento Núm. XXIV - Ano 1146 (ALVARO; LIMA, 2019, p. 128-133).
} 
tempo em que o senhorio episcopal de Sigüenza se mantinha em sintonia com a política da monarquia castelhano-leonesa.

Podemos concluir que as relações mantidas entre o senhorio episcopal seguntino e seus vizinhos pouco sofreram com intervenções da monarquia castelhano-leonesa, mesmo sendo ela, no geral, a principal fonte das doações iniciais às dioceses. Porém, no que diz respeito à intervenção papal, pudemos verificar que, ao menos no caso entre Osma, Tarazona e Sigüenza, o bispo de Roma procurou alcançar um nível de negociação que propiciasse aos envolvidos a harmonização e com isso legitimar-se também como autoridade em solo Ibérico, exercendo nesse caso seu poder senhorial papal.

Finalmente, há de se perceber que a postura de Alfonso VII deve ser vinculada ao seu propósito imperial. Por esse motivo, ele procurou manter um posicionamento neutro nessas tensões específicas entre os senhorios episcopais de seu reino, intrometendo-se o mínimo possível. Mas, ao mesmo tempo, identificamos que sua vinculação à sede seguntina era mais evidente que com as demais, o que explica o nível de negociação estabelecido constantemente entre ele e o senhor bispo de Sigüenza que, quando preciso, não se eximia de reclamar e legitimar sua posição territorial.

Por outro lado, tanto o senhor bispo de Osma quanto o de Tarazona não saíram de todo como derrotados, uma vez que nas esferas da negociação se ganha e perde-se num mesmo ritmo. Para eles, como para Bernardo de Sigüenza, o saldo de ter o poder senhorial-episcopal legitimado compensava as perdas. Por outro lado, o que foi possível conquistar, também, diz respeito ao mínimo de estabelecimento dos limites fronteiriços, mesmo que seu custo tenha sido admitir a presença senhorial de Sigüenza em seus territórios.

\section{Conclusão}

As tensas relações entre os episcopados durante a Idade Média testemunham o quanto a posição senhorial daqueles agentes sociais era uma condição primordial para a manutenção tanto da expansão territorial e de fronteiras como das suas estabilidades. Ao mesmo tempo, as forças que se encontravam ora em atrito, ora em harmonia 
influenciavam o jogo de negociações necessário para ditar o ritmo do cotidiano da Sociedade Senhorial.

Os episcopados, a Igreja de Roma, as monarquias, ou seja, a aristocracia cristã em geral, tinham no senhorio e nas relações de poder que dele frutificavam o modus operandi principal para legitimar autoridade e balancear perdas e ganhos oriundos das disputas por espaço e influência. Mesmo no caso do exercício de poder de mando sobre os integrantes das vilas medievais, nos é possível perceber o quanto estar na posição senhorial era elemento essencial para tais instâncias.

No caso específico do poder senhorial-episcopal, ele se evidencia como um dos aspectos mais importantes para o entendimento da política exercida entre as mais variadas forças institucionais do período centro-medieval, principalmente, se levarmos em consideração o agir do poder específico das instituições doravante citadas.

Além de aspecto histórico das relações de poder e força na Sociedade Senhorial Ibérica na Idade Média Central, o poder senhorial-episcopal nos serve, enquanto arcabouço conceitual, como um instrumento profícuo para manejar as análises sobre o senhorio de maneira menos estanque do que temos testemunhado, afastando-o, inclusive, do seu problemático enunciado feudalismo. Operando a separação entre dois irmãos-siameses que há tempos poderiam seguir caminhos distintos, uma vez que este último tem suas origens mais modernas do que efetivamente medievais enquanto conceito histórico, mesmo com toda sua operacionalidade historiográfica.

Refletir sobre um tipo de poder como o senhorial-episcopal possibilita fugir do "não posicionar-se" e uma calculada defesa frente às muitas acusações de que o revisionismo historiográfico tornou-se algo caricatural e menos importante, quando, na verdade, ainda deve ser o principal ponto de partida na sofrível trajetória de lidar com o cotidiano acadêmico envolto hoje, como no passado, de tabus construídos pelos donos dos tronos de marfim que continuam travando, publicação após publicação, sua guerra de surdos, muitas vezes sem justificar a rejeição de ideias que podem soar como 
velhas, mas que carregam em si a novidade de serem revisadas para também elas se tornarem um som distante, porém que pelo menos foi um dia debatido. ${ }^{84}$

\section{Referências}

\section{Documentação}

ALVARO, Bruno Gonçalves; LIMA, Marcelo Pereira. (Orgs.). Documentação Diplomática da Diocese de Sigüenza entre 1124 e 1151. Edição bilíngue Latim-Português. Salvador: EDUFBA, 2019.

HISTÓRIA COMPOSTELANA. Introducción, traducción, notas y índices de Emma Falque Rey. Madrid: Akal, 1994.

\section{Bibliografia}

ABELS, Richard. The Historiography of a Construct: "Feudalism" and the Medieval Historian. History Compass, Chichester, v. 7, n. 3, p. 1008-1031, 2009.

ALVARO, Bruno Gonçalves. As Veredas da Negociação: Uma Análise Comparativa das Relações entre os Senhorios Episcopais de Santiago de Compostela e de Sigüenza com a Monarquia Castelhano-Leonesa na Primeira Metade do Século XII. 2013. 280f. Tese de Doutorado em História Comparada. Universidade Federal do Rio de Janeiro, Rio de Janeiro, 15 de maio de 2013. Disponível para acesso on-line em: http://objdig.ufrj.br/34/teses/798412.pdf.

ANIZ IRIARTE, Cándido. Restauración de la diócesis de Osma: escuelas Espirituales en los siglos XII-XIII. In: PORTILLO CAPILLA, Teófilo. (Coord.). I Semana de estudios históricos de la Diócesis de Osma-Soria, $15-17$ de septiembre de 1997, Soria, Actas... Soria: Diputación Provincial de Soria, 2000. 2V., v.1, p. 373-416.

AYALA MARTínEZ, Carlos de. Alfonso VII y la Cruzada. Participación de los obispos en la ofensiva reconquistadora. In: MARTíNEZ SOPENA, Pascual; VAL VALDIVIESO, María Isabel del. (Coord.). Castilla y el mundo feudal: homenaje al profesor Julio Valdeón. Valladolid: Junta de Castilla y León/ Consejería de Cultura y Turismo/ Universidad de Valladolid, 2009. 3 v. V. 2. p. 513-529.

AYALA MARTÍNEZ, Carlos de. Reconquista, cruzada y órdenes militares. In: SARASA SÁNCHEZ, Esteban. (Coord.). Las Cinco Villas aragonesas en la Europa de los siglos XII y

\footnotetext{
${ }^{84}$ Dedico esse artigo aos amigos Leandro Duarte Rust, pelas muitas conversas sobre a vida e a Carlos J. Rodríguez Casillas, pela esperança em mim mesmo estando do outro lado do Atlântico. Aos historiadores Bruna Oliveira Mota e Rafael Costa Prata, por criticarem da melhor maneira possível as reflexões aqui presentes: absorvendo-as de maneira historiográfica. À minha supervisora no pós-doutorado: Professora Maria Filomena P. da Costa Coelho e às suas orientandas e seus orientandos da UnB. Finalmente, ao Gregório: sempre e para sempre.
} 
XIII: de la frontera natural a las fronteras políticas y socioeconómicas (foralidad y municipalidad). Zaragoza: Instituición Fernando El Católico, 2007. p. 23-38.

BALOUP, Daniel. Reconquête et croisade dans la Chronica Adefonsi imperatoris (ca. 1150). Cahiers de linguistique et de civilisation hispaniques médiévales, Paris, n. 25, p. 453-480, 2002.

BARTHÉLEMY, Dominique. Senhorio. In: LE GOFF, Jacques; SCHMITT, Jean-Claude. (Coord.). Dicionário Temático do Ocidente Medieval. Bauru, SP; São Paulo, SP: EDUSC; Imprensa Oficial do Estado, 2002. 2v., V. 2, p. 465-476.

BASCHET, Jérôme. A Civilização Feudal: Do ano 1000 à Colonização da América. São Paulo: Globo, 2006.

BLAZQUEZ, Antonio. La Hitación de Wamba. Revista de Archivos, Bibliotecas y Museos, Madrid, n. XVI, p. 67-107, enero-junio, 1907.

BLÁZQUEZ GARBAJOSA, Adrián. La reconquista de Sigüenza y su significación geopolítica regional. Wad-al-Hayara: Revista de estudios de Guadalajara, n. 12, Guadalajara, p. 35-42, 1985.

BLOCH, Marc. A Sociedade Feudal. Lisboa: Edições 70, 2015.

BROWN, Elizabeth A. R. The Tyranny of a Construct: Feudalism and Historians of Medieval Europe. The American Historical Review, Oxford, v. 79, n. 4, p. 1063-1088, oct., 1974.

CUENCA TORIBIO, José Manuel. La reconquista y la formación de la comunidad histórica española. In: ADÃO DA FONSECA, Luís; AMARAL, Luis Carlos; FERREIRA SANTOS, Maria Fernanda. (Coords.). Os reinos ibéricos na Idade Média: livro de homenagem ao professor doutor Humberto Carlos Baquero Moreno. Porto: Livraria Civilização, 2003. 3 v. V.2, p. 695-701.

DUBY, Georges. La féodalité? Une mentalité médiévale. Annales. Économies, Sociétés, Civilisations, Paris, n. 4, p. 765-771, 1958.

DUBY, Georges; LARDREAU, Guy. Diálogos sobre a Nova História. Lisboa: Dom Quixote, 1989.

ESCALONA MONGE, Julio. Misericordia regia, es decir, negociemos: Alfonso VIl y los Lara en la "Chronica Adefonsi imperatoris". In: ALFONSO ANTÓN, María Isabel; ESCALONA MONGE, Julio; MARTIN, Georges. (Coord.). Lucha política: condena y legitimación en la España medieval. Lyon: ENS Éditions, 2004. p. 101-152.

ESTEPA DÍEZ, Carlos; PÉREZ-ALFARO, Cristina Juliar. (Coord.). Los Señoríos de Behetría. Madrid: Consejo Superior de Investigaciones Científicas, 2001.

ESTEPA DÍEZ, Carlos. Frontera, nobleza y señoríos en Castilla: el señorío de Molina (siglos XII-XIII). Studia historica. Historia medieval, Salamanca, n. 24, p.15-86, 2006. 
FERNÁNDEZ CONDE, Francisco Javier. El papel de la monarquía en la consolidación señorial del obispo de Oviedo. Studia historica. História medieval, Salamanca, n. 25, p. 67-87, 2007.

GANSHOF, François-Louis. Que é o feudalismo? Mira-Sintra: Europa-América, 1976. GARCÍA FITZ, Francisco. La Reconquista. Granada: Editorial Universidad de Granada, 2010.

GIVEN, James B. Inquisition and Medieval Society: Power, Discipline and Resistance in Languedoc. Ithaca \& Londres: Cornell University Press, 1997.

GONZALEZ GARCIA, Vicente José. La Hitación de Wamba: confirmación de los linderos diocesanos en el año 676. Magister: Revista miscelánea de investigación, Oviedo, n. 11, p. 173-215, 1993.

GONZÁLEZ GARCIA, Vicente José. El obispo D. Pelayo y su influencia en el estudio de las cuestiones altomedievales. Magister: Revista miscelánea de investigación, Oviedo, n. 5, p. 263-291, 1987.

GONZÁLEZ GONZÁLEZ, Julio. Fijación de la Frontera Castelhano-leonesa en el Siglo XII. En la España Medieval, Madrid, n. 2, p. 411-424, 1982.

GUERREAU, Alain. El Futuro de un Pasado: La Edad Media en el Siglo XXI. Barcelona: Crítica, 2002.

GUERREAU, Alain. El Concepto de Feudalismo: Génesis, evolución y significación actual. In: ESTEPA DÍEZ, Carlos; PLACIDO, Domingo; TRIAS, Juan. Transiciones en la antigüendad y feudalismo. Madrid: Fundación de Investigaciones Marxistas, 1998. p. 91-116.

GUERREAU, Alain. O Feudalismo: Um horizonte teórico. Lisboa: Edições 70, 1982.

JOSÉ RUI, Adailson; VIÇOSE, Jordano. Diego Gelmírez. In: NASCIMENTO, Renata Cristina de Souza; SOUZA, Guilherme Queiroz de. (Orgs.). Dicionário: Cem Fragmentos Biográficos - A Idade Média em Trajetórias. Goiânia: Tempestiva, 2020. p. 239-244.

KULA, Witold. Teoria economica del sistema feudale. Proposta di un modello. Torino: Einaudi, 1970.

MARTÍN VISO, Iñaki. Organización episcopal y poder entre la Antigüedad Tardía y el Medievo (Siglos V-XI): Las sedes de Calahorra, Oca y Osma. Iberia, La Rioja, n. 2, p. 151190, 1999.

NIETO SORIA, José Manuel. El carácter feudal de las relaciones monarquía-episcopado en el ámbito castellano: el caso del obispado de Cuenca. En la España medieval, Madrid, n. 3, p. 197-218, 1982.

ORTIZ DE VILLAJOS, Salvador de Moxó. Feudalismo, señorío y nobleza en la Castilla medieval. Madrid: Real Academia de la Historia, 2000. 
PECES RATA, Felipe Gil. Litigios y concordias entre los obispos de Sigüenza y Osma, sobre límites de sus respectivos obispados, en la sección diplomática de la Catedral de Sigüenza. Memoria ecclesiae (Asociación de Archiveros de la Iglesia en España), Madrid, n. 27, p. 547-552, 2005.

REYNOLDS, Susan. Fiefs and Vassals: The Medieval Evidence Reinterpreted. Oxford: Oxford University Press, 1994.

RíOS SALOMA, Martín Federico. La Reconquista en la historiografía española contemporánea. Madrid/ México, D.F.: Silex/ Universidad Nacional Autónoma de México, 2013;

RÍOS SALOMA, Martín Federico. La Reconquista: Una construcción historiográfica (siglos XVI-XIX). México, D.F.; Madrid: Universidad Nacional Autónoma de México, Instituto de Investigaciones Históricas; Marcial Pons História, 2011;

RíOS SALOMA, Martín Federico. La "Reconquista": una aspiración peninsular? Estudio comparativo entre dos tradiciones Historiográficas. Bulletin du centre d'études médiévales d'Auxerre, Auxerre, n. 2, 2008;

RÍOS SALOMA, Martín Federico. De la Restauración a la Reconquista: la construcción de un mito nacional (Una revisión historiográfica. Siglos XVI-XIX). En la España medieval, Madrid, n. 28, p. 379-414, 2005.

RUST, Leandro Duarte. Bispos Guerreiros: Violência e Fé antes das Cruzadas. Petrópolis, RJ: Vozes, 2018.

RUST, Leandro Duarte. Colunas de São Pedro: A Política Papal na Idade Média Central. São Paulo: Annablume, 2011.

SABATÉ I CURULL, Flocel. Frontera peninsular e identidad (siglos IX-XII). In: SARASA SÁNCHEZ, Esteban. (Coord.). Las Cinco Villas aragonesas en la Europa de los siglos XII y XIII: de la frontera natural a las fronteras políticas y socioeconómicas (foralidad y municipalidad). Zaragoza: Instituición Fernando El Católico, 2007. p. 47-94.

SANCHEZ ALBORNOZ, Claudio. En torno a los orígenes del feudalismo. Buenos Aires: Eudesa, 1979. 3v.

SARASA SÁNCHEZ, Esteban; SERRANO MARTÍN, Eliseo. (Eds.). Estudios sobre señorío y feudalismo (Homenaje a Julio Valdeón). Zaragoza: Institución Fernando el Católico, 2010.

SEVILLA MUÑOZ, Julia. Una consecuencia de la reconquista de Guadalajara: Ia repoblación de Sigüenza por un obispo aquitano. Wad-al-Hayara: Revista de estudios de Guadalajara, Guadalajara, n. 12, p. 43-56, 1985.

SOTO RÁBANOS, Jose María. La frontera: connotaciones jurídico-canónicas (siglos XII$X V$ ). In: SEGURA ARTERO, Pedro. (Coord.). Congreso la Frontera Oriental Nazarí como 
Sujeto Histórico (S.XIII-XVI), Lorca-Vera, 22 a 24 de noviembre de 1994, Actas... Almería: Instituto de Estudios Almerienses, 1997. p. 213-220.

TAMBO MOROS, Javier. La diócesis de Tarazona durante la Edad Media y los archivos eclesiásticos de Tarazona. Cuadernos de estudios borjanos, Zaragoza, n. 49, p. 89-112, 2006.

VALDEÓN BARUQUE, Julio. El feudalismo. Madrid: Alba, 1999.

VANOLI, Alessandro. L'invenzione della Reconquista. Note sulla storia di una parola. Reti Medievali Rivista, Napoli, n. 9, p. 1-13, 2008.

VILLAR GARCÍA, Luis Miguel. Un conflicto interdiocesano en la Edad Media: Palencia y Segovia y la división de Wamba. In: I Congreso de Historia de Palencia, 3-5 Diciembre 1985, Castillo de Monzón de Campos, Actas... Palencia: Diputación Provincial de Palencia, 1987. 4V., v. 2 (Fuentes documentales y Edad Media), p. 385-400.

VIÇOSE, Jordano. História e Poder: uma análise dos escritos de Giraldo e Pedro Márcio sobre as revoltas em Santiago de Compostela (séc. XII). In: MÜLLER, Cícera Leyllyany F. L. F.; TOMAZELLI, Roni. Medievalidades e Humanidades: O Tempo e o Espaço na História. Vila Velha, ES: LETAMIS Laboratório de Estudos Tardo Antigos e Medievais Ibéricos e Sefaradis - UFES, 2020. p. 67-85.

WICKHAM, Chris. El Legado de Roma. Una História de Europa de 400 a 1000. Barcelona: Pasado \& Presente, 2013. 